forms zur Lösung*), von dem mit 10 Proc. Alkohol versetzten aber nur 111 Thle.

Der Verfasser hebt hervor, dass die Löslichkeit eines mit Narcotin verunreinigten Morphiums (Narcotin löst sich bekanntlich in Chloroform schr leicht) eine viel grössere sei, und glaubt, die falschen Angaben mancher Lehrbücher rührten vielleicht daher, dass mit nicht ganz reinem Morphium operirt worden sei.

\title{
Zur quantitativen Bestimmung des Alizarins in Gemengen mit
} Isopurpurin und Flavopurpurin. Wie ich auf Seite 210 dieses Heftes berichtet habe, bedienen sich E. Schunck und H. Römer der fractionirten Sublimation um das Alizarin, welches bei $110^{0}$ zu sublimiren anfängt, behufs qualitativer Nachweisung von Flavopurpurin und Isopurpụrin zu trennen, welche erst bei $160^{\circ}$ resp. $170^{\circ} \mathrm{zu}$ sublimiren beginnen. Das Gemenge wird zwischen zwei durch einen wenige Millimeter dicken Bleiring getrennten Glasplatten im Luftbade erhitzt.

Da selbst bei einer Temperatur von $200^{\circ}$ keine Verkohlung eintrat, so glaubten die Verfasser**) ihre Methode auch zur quantitativen Bestimmung des Alizarins in Gemischen der genannten Körper anwenden zu sollen. Es erschien dies in so fern von Wichtigkeit, als das Alizarin des Handels fast immer die beiden Purpurine beigemengt enthält und bis jetzt eine Methode den wirklichen Alizaringehalt im Handelsproduct leicht festzustellen nicht existirt.

Die Verfasser wendeten zu dem betreftenden Versuch ein Gemisch von reinem Flavopurpurin und Alizarin an und erhizzten dasselbe andauernd auf circa $140^{\circ}$. Von Zeit zu Zeit wurde das Sublimat von der oberen Glasplatte entfernt und so lange von neuem erhitzt, bis sich keine Spur desselben mehr gebildet hatte. - Dies ist leicht unter dem Mikroskop oder durch Betupfen der Glasplatte mit Kalilauge zu erkennen. Das Gewicht des Rückstandes blieb dann auch ein constantes.

Die Mischung der Verfasser bestand aus 90,91 Proc. Flavopurpurin und 9,09 Proc. Alizarin. Die Analyse ergab 8,91 Proc. Alizarin.

Will man das Handelsalizarin auf diese Weise untersuchen, so wird man, um scharfe Zahlen zu erhalten, gut thun, zunächst etwa vorhandenes Anthrachinon, Oxyanthrachinon, Anthra- und Isoanthraflavinsäure $\mathrm{zu}$ entfernen, was ja leicht zu bewerkstelligen ist.

*) v. d. Burg's Resultate bestätigen also die Angabe von Pettenk ofer, dass das Morphium in Chloroform sehr schwer löslich ist. (Vgl. R. Fresenius Anl. z. qualitat. chem. Analyse 14. Aufl., p. 431.) H. F.

**) Ber. d. deutsch. chem. Gesellsch. z. Berlin 13, 42. 